\title{
Transgenic Tomato Plants that Overexpress a Gene for NADH-dependent Glutamate Dehydrogenase (legdh1)
}

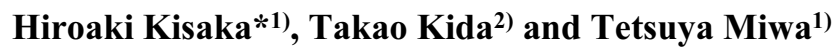 \\ 1) Research Institute for Health Fundamentals, Ajinomoto Co. Inc., 1-1 Suzuki, Kawasaki, Kawasaki, Kanagawa 210-8681, Japan \\ 2) Basic Research Laboratory, Ajinomoto Co. Inc. (present address: Life Science Laboratory, Ajinomoto Co. Inc.) 1-1 Suzuki, Kawasaki, \\ Kawasaki, Kanagawa 210-8681, Japan
}

\begin{abstract}
Tomato plants were transformed with a plasmid that included a legdh1 gene for NADH-dependent glutamate dehydrogenase (NADH-GDH) from Lycopersicon esculentum Mill. coupled, in the sense orientation, with the constitutively active $35 \mathrm{~S}$ promoter from cauliflower mosaic virus. Three independent transformants were obtained. In these transgenic lines, high-level expression of legdh1 mRNA was detected in the leaves, and the NADH-GDH activity in the leaves of the transgenic plants was approximately twice that in the leaves of the non-transgenic plant. In the transgenic tomato fruits examined for six successive weeks after flowering, the levels of total free amino acids were higher (2.1- to 2.3-fold) than those in the controls. In particular, the level of glutamate was about twice that in the control fruits.
\end{abstract}

Key Words: glutamate dehydrogenase, Lycopersicon esculentum Mill., amino acids, ripening fruits, transgenic tomato.

\section{Introduction}

Tomato (Lycopersicon esculentum Mill.), which is an important food in many parts of the world, displays an attractive color, flavor and considerable versatility. Tomatoes are used fresh and after processing and, in both cases, flavor and taste are important. These characteristics are associated mainly with sugars, amino acids, organic acids, and volatile compounds. During the ripening of fruits, taste and flavor intensify and changes in the levels of these various compounds are to be expected. Free amino acids are essential nonvolatile compounds that contribute to the overall taste of many foods and glutamate, in particular, contributes to the taste of tomatoes (Fuke and Konosu 1991). However, little is known about the metabolism of amino acids during the ripening of tomato fruit.

Glutamate is an $\alpha$-amino acid that is synthesized in the first step of the nitrogen metabolism in higher plants. Glutamine and asparagine, derived from glutamate, are distributed to tissues through the phloem and used for the synthesis of other amino acids and proteins. In higher plants, glutamate occurs at high concentrations in the phloem, which also transports the products of photosynthesis, such as sucrose, and other amino acids. Glutamate occurs at high concentrations in edible parts of plants, for example, at $2,800 \mathrm{nmol} / \mathrm{g}$ fresh weight $(17.2 \%$ of total free amino acids) in tomato fruits (cv. Platense; Boggio et al. 2000).

Communicated by H. Yamagishi

Received December 9, 2005. Accepted February 19, 2007.

*Corresponding author (e-mail: hiroaki_kisaka@ajinomoto.com)
The enzymes involved in the biosynthesis of amino acids during the ripening of tomato fruits have been investigated in detail. Gallardo et al. (1988) reported that the complement of isoforms of glutamine synthase (GS) varied in the ripening tissues of tomato. Levels of NADH-dependent glutamate synthase (NADH-GOGAT) and ferredoxinGOGAT, two enzymes that catalyze the synthesis of glutamate, decreased gradually during the ripening of tomatoes (Gallardo et al. 1993). A decrease in the levels of GS during fruit ripening and concomitant increases in the levels of $\mathrm{NADH}$-dependent glutamate dehydrogenase (NADH-GDH) and aspartate aminotransferase have also been reported (Boggio et al. 2000). GDH catalyses the reversible amination of 2-oxoglutarate to glutamate. We considered that it would be important to enhance the GDH activity to accumulate the glutamate in ripening fruits.

Although transgenic plants have been produced by the introduction of a $g d h A$ gene for glutamate dehydrogenase (GDH), but when the gdhA gene derived from $E$. coli was introduced into tobacco and corn to confer resistance to the herbicide phosphinothricin, the level of glutamic acid in roots increased only 1.3- to 1.4-fold (Lightfoot and Long 1999). In transgenic tobacco plants with the $g d h A$ transgene, ${ }^{13} \mathrm{~N}$ labeling of glutamate and glutamine increased significantly (Mungur et al. 2005). We also reported that the glutamate content of the fruits of the transgenic tomato plants that harbored a $g d h A$ gene for NADPH-dependent GDH from Aspergillus nidulans was approximately twice that of the wild type (Kisaka and Kida 2003). However, this gdhA gene encoded NADPH-dependent GDH and locked a signal peptide sequence targeted to mitochondria. 
The GDH protein is a hexamer consisting of two subunit polypeptides that differ slightly in mass and charge (Loulakakis-Angelakis 1991, 1996). Two GDH cDNAs have been cloned from Arabidopsis thaliana (Melo-Oliveira et al. 1996, Turano et al. 1997) and Nicotiana plumbaginifolia (Ficarelli et al. 1999). These proteins are NADH-dependent types, and contain a signal peptide sequence targeted to mitochondria. We considered that it would be very important for the GDH function to be NADH-dependent and to act in mitochondria in higher plants.

Purnell et al. (1997) reported that the GDH cDNA (legdh1) was cloned from tomato, and that the legdh1 gene is consisted of a single copy in tomato and contained a signal peptide sequence targeted to mitochondria. The gene might be regulated by post-transcriptional modification in tomato. In the present study, attempts were made to introduce the legdh1 gene from tomato, which encodes NADH-dependent $\mathrm{GDH}$, into tomato to increase the level of glutamate in fruits. We observed an increase in the levels of free amino acids, and, in particular, of glutamate, in the resultant tomato fruits.

\section{Materials and Methods}

\section{Construction of plasmid}

The gene for NADH-dependent-GDH (legdh1) was isolated from Lycopersicon esculentum Mill. (Purnell et al. 1997). Two primers (5'-TCT AGA ATG AAT GCT TTA GCA GCA ACT-3' and 5'-GAG CTC TTA CGC CTC CCA TCC TCG AAG-3') were used to obtain cDNA fragments by RT-PCR. As expected, PCR ( 30 cycles of incubation at $94^{\circ} \mathrm{C}$ for $45 \mathrm{sec}, 54^{\circ} \mathrm{C}$ for $30 \mathrm{sec}$, and $72^{\circ} \mathrm{C}$ for $90 \mathrm{sec}$, with a final extension at $72^{\circ} \mathrm{C}$ for $10 \mathrm{~min}$ ) generated a 1,300 -bp product that was cloned into the pCR2.1 vector (Invitrogen, San Diego, CA, USA). The resultant plasmid was used to transform competent $E$. coli cells (TOP10; Invitrogen). The legdh1 gene was ligated into the binary vector, pIG121-Hm (Fig. 1). Agrobacterium tumefaciens strain EHA101 (Hood et al. 1986) was transformed with the resultant plasmid.

\section{Transformation of tomato}

Tomato (Lycopersicon esculentum Mill.) was transformed by Agrobacterium-mediated gene transfer via the inoculation on leaf disks (Roekel et al. 1993). Shoots regenerated on MS medium (Murashige and Skoog 1962) that had been supplemented with $2 \mathrm{mg} / 1$ trans-zeatin, $0.1 \mathrm{mg} / 1$ indoleacetic acid (IAA), $50 \mathrm{mg} / \mathrm{l} \mathrm{kanamycin} \mathrm{and} 300 \mathrm{mg} / \mathrm{l}$ cefotaxime, were transferred to a rooting medium (MS medium supplemented with $50 \mathrm{mg} / \mathrm{l} \mathrm{kanamycin}$ and $300 \mathrm{mg} / \mathrm{l}$ cefotaxime). Rooted transformants $\left(\mathrm{T}_{0}\right)$ were grown to maturity in garden soil in a growth chamber under $16 \mathrm{~h}$ exposure to white light from fluorescent lamps, daily at $25^{\circ} \mathrm{C}$. Seeds harvested from each transgenic plant were selected on MS medium supplemented with $250 \mathrm{mg} / \mathrm{l}$ kanamycin and $300 \mathrm{mg} / \mathrm{l}$ cefotaxime. Selected $\mathrm{T}_{1}$ plants were grown to maturity in garden soil ( $1 \mathrm{~kg}$ per pot) in a growth chamber, as described above.

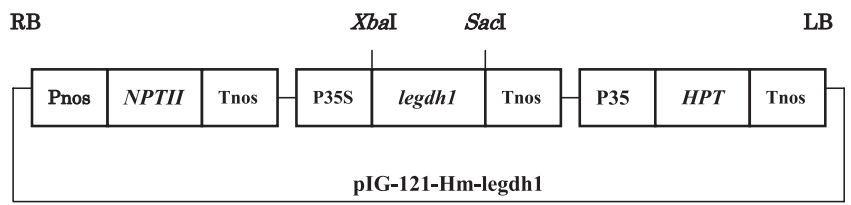

$\begin{array}{lllll}M & 1 & 2 & 3 & 4\end{array}$

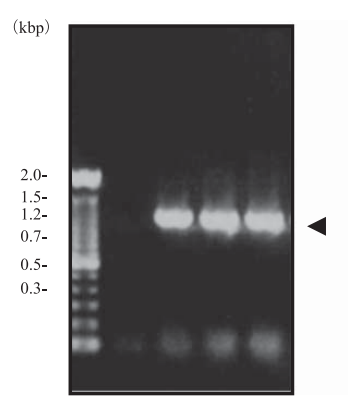

B

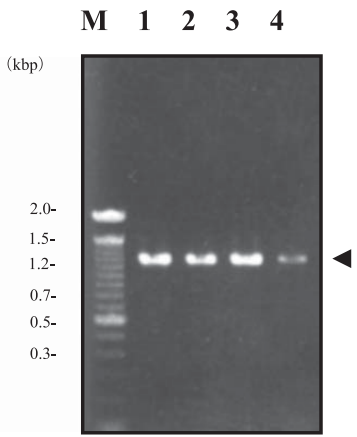

C
Fig. 1. A. Construction of the binary Ti plasmid pIG121-Hm-legdh1. NPTII gene, gene for neomycin phosphotransferase; legdh1 gene, gene for glutamate dehydrogenase from Lycopersieon esculentum Mill.; HPT gene, gene for hygromycine phosphotransferase; Pnos, promoter of gene for nopaline synthase; Tnos, transcription terminator region of gene for nopaline synthase; P35S, promoter of $35 \mathrm{~S}$ transcript from cauliflower mosaic virus; RB, right border; and LB, left border. B. Genomic PCR analysis with nopaline synthase promoter gene and terminator gene-specific primers. Lane 1, Non-transgenic tomato plant; lanes 2 to 4, transgenic tomato lines 1, 2 and 3, respectively. C. RT-PCR analysis. RNA was extracted from tomato fruits and legdhl gene-specific primers were used for PCR. Lanes 1 to 3, Transgenic tomato lines 1, 2 and 3, respectively; lane 4, non-transgenic tomato plant.

\section{Isolation of DNA and analysis by PCR}

Total DNA was prepared from the leaves of transgenic tomato and non-transgenic tomato plants as described by Honda and Hirai (1990). Amplification by PCR was performed using two primers; 5'-CCC TCG GTA TCC AAT TAG AG-3' (nopaline synthase promoter gene-specific primer) and 5'-CGG GGG GTG GGC GAA GAA CTC CAG-3' (nopaline synthase terminator gene-specific primer), with 35 cycles of incubation at $94^{\circ} \mathrm{C}$ for $45 \mathrm{sec}$, at $54^{\circ} \mathrm{C}$ for $30 \mathrm{sec}$, and at $72^{\circ} \mathrm{C}$ for $90 \mathrm{sec}$, with final a extension at $72^{\circ} \mathrm{C}$ for $10 \mathrm{~min}$.

\section{Isolation of $R N A$ and analysis by reverse transcription and PCR (RT-PCR)}

After extraction of RNA from frozen leaves, the isolated RNA was precipitated in $4 \mathrm{M} \mathrm{LiCl}$ for $2 \mathrm{~h}$ at $0^{\circ} \mathrm{C}$ to remove traces of DNA and small RNAs. After treatment of the RNA with DNase, first-strand cDNA was prepared using an RNA-RCR kit (Takara Bio Co., Shiga, Japan), and RT-PCR cycling was performed as described before, using legdh1 
gene-specific primers; 5'-TCT AGA ATG AAT GCT TTA GCA GCA ACT-3' and 5'-GAG CTC TTA CGC CTC CCA TCC TCG AAG-3'

\section{Assay of aminating activity of $G D H$}

Leaf tissues $(0.5 \mathrm{~g})$, cultured on MS medium for one month, were ground using a mortar and a pestle at $4^{\circ} \mathrm{C}$ in five volumes of ice-cold extraction buffer [200 mM Tris$\mathrm{HCl}$ (pH 8.0), $10 \mathrm{mM}$ L-cysteine, $14 \mathrm{mM} \beta$-mercaptoethanol, $0.5 \mathrm{mM}$ phenylmethylsulfonyl fluoride (PMSF), 0.5\% (v/v) Triton X-100; Loulakakis and Roubelakis-Angelakis 1991]. The homogenate was centrifuged at $10,000 \mathrm{rpm}$ for $30 \mathrm{~min}$. The supernatant was filtered through a Ultrafree- 0.5 filter with Biomax-10 (Millipore, Tokyo, Japan) to remove proteins of less than $10 \mathrm{kDa}$ and the filter was washed three times with the buffer solution. The upper solution was used for assays of the enzymatic activity. The specific activity of aminating NADH-GDH was quantified by measuring the rate of oxidation of $\mathrm{NADH}$ during reductive amination of 2oxoglutarate at a saturating concentration of the substrate. The reaction mixture consisted of $100 \mathrm{mM}$ Tris- $\mathrm{HCl}(\mathrm{pH}$ 8.5), $20 \mathrm{mM}$ 2-oxoglutarate, $1.0 \mathrm{mM} \mathrm{CaCl}_{2}$ and $0.2 \mathrm{mM}$ $\mathrm{NADH}$. The rate of change in absorption was monitored at $340 \mathrm{~nm}$ for $1 \mathrm{~min}$ before and for $1 \mathrm{~min}$ after the addition of ammonium chloride to a final concentration of $200 \mathrm{mM}$. Assays were performed at $25^{\circ} \mathrm{C}$.

\section{Amino acid analysis}

Transgenic $\left(T_{1}\right)$ and non-transgenic tomato fruits from the first fruit cluster, harvested six weeks after flowering, were used for the analysis of amino acids. Three plants of each line were used for amino acid analysis. Amino acid levels in the leaves of the $T_{1}$ and non-transgenic tomato plants, which were obtained from one-month-old plants after subculture on MS medium, were also analyzed. Two or more plants were used for amino acid analysis. Macerated tissue samples were shaken in five volumes of $80 \%(\mathrm{v} / \mathrm{v})$ ethanol at $80^{\circ} \mathrm{C}$ for $30 \mathrm{~min}$. After centrifugation of the mixture for 10 min at $8,000 \mathrm{rpm}$, the ethanol fraction was collected and the same process was repeated two more times. The ethanol extract was evaporated to dryness, and the resultant free amino acids in the residue were treated with ethyl ether and dried again. Finally, the amino acids were dissolved in $0.02 \mathrm{~N} \mathrm{HCl}$ and the solution was filtered through a $0.20-\mu \mathrm{m}$ UltrafreeMC filter (Millipore) and analyzed with an automated aminoacid analyzer (L-8800; Hitachi Ltd., Tokyo, Japan).

\section{Results}

\section{Selection of $T_{0}$ transgenic plants and analysis by PCR}

The binary vector pIG121-Hm with an inserted legdh1 gene was used to generate tomato transformants $\left(\mathrm{T}_{0}\right)$ by Agrobacterium-mediated transformation (Fig. 1A). Three $\mathrm{R}_{0}$ plants were regenerated. DNA was extracted from the leaves of the three $\mathrm{T}_{0}$ plants and from those of a non-transgenic plant. Amplification was performed by PCR with the no- paline synthase promoter gene and terminator gene-specific primers, as described in "Materials and Methods". All the transgenic plants yielded amplified fragments of $1.0 \mathrm{kbp}$ (Fig. 1B). These $T_{0}$ plants were grown to maturity in garden soil in a growth chamber under $16 \mathrm{~h}$ exposure to white light from fluorescent lamps, daily at $25^{\circ} \mathrm{C}$, and their fertility was identical to that of the non-transgenic plant. Seeds were harvested from each transgenic plant.

\section{Selection of $T_{1}$ transgenic plants and analysis by RT-PCR}

The harvested $T_{1}$ seeds were allowed to germinate on MS medium supplemented with $250 \mathrm{mg} / \mathrm{l} \mathrm{kanamycin} \mathrm{and}$ $300 \mathrm{mg} / \mathrm{l}$ cefotaxime. Three independent transformants, namely, one from each of three different $\mathrm{T}_{0}$ plants, designated as T-gdh nos. 1, 2 and 3, were clearly resistant to kanamycin. These transgenic lines $\left(T_{1}\right)$ and a non-transgenic control $\left(\mathrm{R}_{1}\right)$, which was the offspring of a plant that had been regenerated from leaf disks, were used in subsequent experiments.

Total RNA was extracted from the leaves of the three transgenic plants and the non-transgenic control plant one month after germination. Analysis by RT-PCR indicated that the level of expression of legdh1 mRNA in the transgenic plants was higher than that in the non-transgenic plant (Fig. 1C).

\section{Assay of the aminating activity of GDH}

Differences in the activity of GDH in the various plants were confirmed by quantitation of the specific activity of NADH-dependent GDH in the crude extracts, which was achieved by monitoring the rate of oxidation of $\mathrm{NAD}^{+}$spectrophotometrically. The specific activity of NADH-GDH from the transgenic tomato lines was approximately twice that of the enzyme from the non-transgenic control plant (Table 1).

\section{Amino acid analysis}

We examined the fruits of the non-transgenic tomato plant to determine the stage at which the levels of amino acids were relatively stable. We determined the levels of amino acids in the fruits in the first-fruit clusters at different stages of ripening (Fig. 2). In the four-week-old fruits, which

Table 1. Activity of NADH-GDH in $\mathrm{T}_{1}$ transgenic and nontransgenic tomato leaves

\begin{tabular}{cc}
\hline \hline Lines & $\begin{array}{c}\text { Activity of NADH-GDH } \\
\text { (nmol/min. mg protein) }\end{array}$ \\
\hline $\begin{array}{c}\text { Non-transgenic tomato plant } \\
\text { Transgenic tomato lines }\end{array}$ & $78.0 \pm 13.2^{1)}$ \\
T-gdh 1 & $180.2 \pm 41.6^{* *}$ \\
T-gdh 2 & $160.0 \pm 30.2^{* *}$ \\
T-gdh 3 & $265.6 \pm 53.4^{* *}$ \\
\hline
\end{tabular}

1) Values are means \pm S.E.M. of results, from three separate experiments.

** Significant difference at the $1 \%$ level when compared with the non-transgenic plant (Student's $t$-test). 


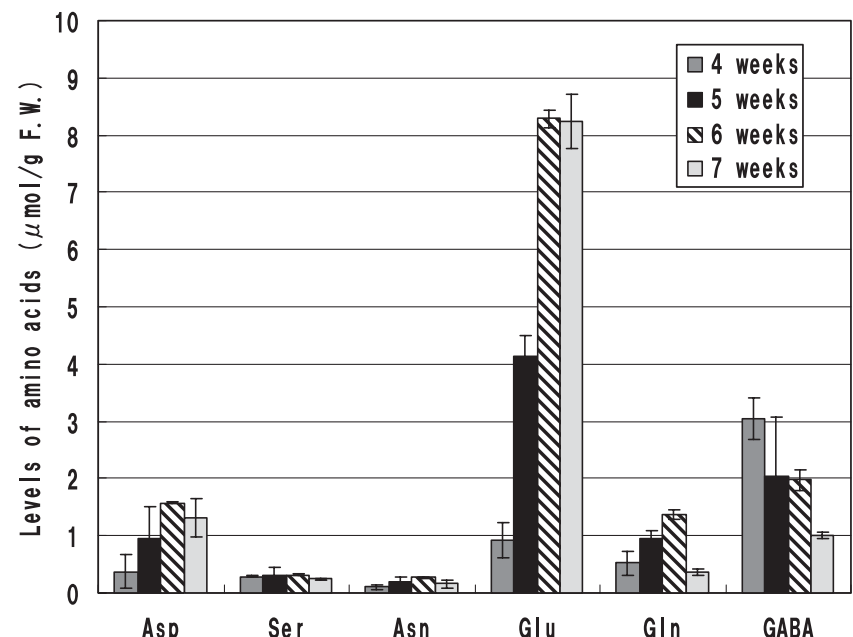

Fig. 2. Levels of amino acids in non-transgenic tomato fruits from four to seven weeks after flowering, as indicated (results are means \pm S.E.M; $\mathrm{n}=3$ ).

were green, $\gamma$-aminobutyric acid (GABA) was the predominant amino acid. During ripening, the color of the fruits changed to orange and auxesis ceased five weeks after flowering. In the six-week-old fruits, which were red, the levels of GABA were lower and those of glutamate were considerably higher. The epidermis of the seven-week-old fruits was broken but the levels of amino acids were similar to those in the six-week-old fruits. Therefore, we used six-week-old fruits to compare the levels of amino acids between transgenic and non-transgenic tomato plants.

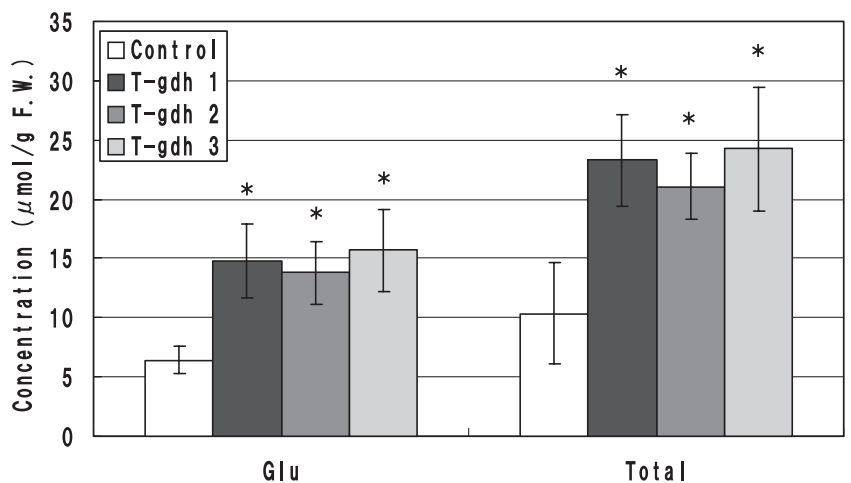

Fig. 3. Levels ( $\mu \mathrm{mol} / \mathrm{g} \mathrm{F.W.)} \mathrm{of} \mathrm{glutamate} \mathrm{and} \mathrm{total} \mathrm{free} \mathrm{amino} \mathrm{acids}$ in $T_{1}$ transgenic and non-transgenic tomato fruits harvested six weeks after the first flowering $(\mathrm{n}=3)$.

* Significant difference at the 5\% level when compared with the non-transgenic plant (Student's $t$-test).

The total amount of free amino acids in the transgenic tomato fruits was approximately 2.1 to 2.3 fold higher than that in the non-transgenic fruits. In particular, the level of glutamate was twice that in the control fruits (Fig. 3). Levels of aspartic acid, asparagine and alanine were also elevated in the transgenic tomato fruits (Table 2). We investigated the levels of amino acids in the shoots that had been grown on MS medium for one month. The levels of asparagine and glutamine in the transgenic tomato leaves were higher than those in the corresponding non-transgenic tomato leaves (Table 3).

Table 2. Levels ( $\mu \mathrm{mol} / \mathrm{g} \mathrm{F.W.)} \mathrm{of} \mathrm{amino} \mathrm{acids} \mathrm{in} \mathrm{T}_{1}$ transgenic and non-transgenic tomato fruits harvested six weeks after the first flowering

\begin{tabular}{cccccc}
\hline \hline & Asp & Thr & Ser & Asn & Glu \\
\hline Non-transgenic plant & $1.09 \pm 0.48$ & $0.10 \pm 0.03$ & $0.22 \pm 0.05$ & $0.18 \pm 0.01$ & $6.42 \pm 1.16$ \\
T-gdh 1 & $2.61 \pm 0.51^{*}$ & $0.28 \pm 0.05^{* *}$ & $0.56 \pm 0.12^{*}$ & $0.48 \pm 0.02^{* *}$ & $14.74 \pm 3.12^{*}$ \\
T-gdh 2 & $2.41 \pm 0.51^{*}$ & $0.20 \pm 0.04^{*}$ & $0.44 \pm 0.13$ & $0.30 \pm 0.01^{* *}$ & $13.81 \pm 2.64^{*}$ \\
T-gdh 3 & $2.85 \pm 0.60^{*}$ & $0.22 \pm 0.05^{*}$ & $0.46 \pm 0.11^{*}$ & $0.31 \pm 0.07^{*}$ & $15.70 \pm 3.47^{*}$ \\
\hline Non-transgenic plant & Gln & Gly & Ala & Val & Met \\
T-gdh 1 & $0.44 \pm 0.33$ & $0.01 \pm 0.01$ & $0.29 \pm 0.11$ & $0.09 \pm 0.05$ & $0.02 \pm 0.01$ \\
T-gdh 2 & $0.79 \pm 0.65$ & $0.05 \pm 0.03$ & $0.91 \pm 0.56$ & $0.16 \pm 0.05$ & $0.03 \pm 0.01$ \\
T-gdh 3 & $0.43 \pm 0.37$ & $0.06 \pm 0.02^{*}$ & $0.70 \pm 0.35^{* *}$ & $0.16 \pm 0.06$ & $0.03 \pm 0.01$ \\
& Ile & $0.04 \pm 0.01^{*}$ & $0.69 \pm 0.05^{*}$ & $0.12 \pm 0.05$ & $0.03 \pm 0.01$ \\
\hline Non-transgenic plant & $0.04 \pm 0.02$ & $0.04 \pm 0.01$ & $0.05 \pm 0.01$ & $0.09 \pm 0.04$ & GABA \\
T-gdh 1 & $0.10 \pm 0.03$ & $0.12 \pm 0.05$ & $0.12 \pm 0.02^{* *}$ & $0.25 \pm 0.14$ & $0.96 \pm 0.11$ \\
T-gdh 2 & $0.11 \pm 0.03$ & $0.11 \pm 0.04$ & $0.07 \pm 0.01$ & $0.20 \pm 0.02^{*}$ & $1.31 \pm 0.96$ \\
T-gdh 3 & $0.10 \pm 0.02$ & $0.10 \pm 0.02^{* *}$ & $0.06 \pm 0.01$ & $0.31 \pm 0.05^{* *}$ & $2.24 \pm 0.85$ \\
\hline Non-transgenic plant & Lys & His & Arg & Pro & Total \\
T-gdh 1 & $0.04 \pm 0.02$ & $0.13 \pm 0.04$ & $0.12 \pm 0.08$ & $0.04 \pm 0.02$ & $10.36 \pm 4.24$ \\
T-gdh 2 & $0.30 \pm 0.26$ & $0.29 \pm 0.17$ & $0.16 \pm 0.10$ & $0.05 \pm 0.03$ & $23.29 \pm 3.88^{*}$ \\
T-gdh 3 & $0.13 \pm 0.01^{* *}$ & $0.27 \pm 0.06^{*}$ & $0.07 \pm 0.05$ & $0.08 \pm 0.05$ & $21.09 \pm 2.80^{*}$ \\
\hline
\end{tabular}

Values are means \pm S.E.M. of results from three fruits in each case.

** Significant difference at the $1 \%$ level when compared with the non-transgenic plant.

* Significant difference at the 5\% level when compared with the non-transgenic plant (Student's $t$-test). 
Table 3. Levels ( $\mu \mathrm{mol} / \mathrm{g} \mathrm{F.W.)} \mathrm{of} \mathrm{amino} \mathrm{acids} \mathrm{in} \mathrm{T}_{1}$ transgenic and non-transgenic tomato leaves. $\mathrm{T}_{1}$ seedlings were selected on MS medium supplemented with $250 \mathrm{mg} / \mathrm{l} \mathrm{kanamaycin} \mathrm{and} 300 \mathrm{mg} / \mathrm{l}$ cefotaxime, and then the shoot apex was cultured on MS medium without antibiotics. After one month, free amino acids were extracted from the leaves of the plants.

\begin{tabular}{|c|c|c|c|c|c|}
\hline & Asp & Thr & Ser & Asn & Glu \\
\hline Non-transgenic plant & $0.82 \pm 0.04$ & $0.23 \pm 0.01$ & $0.68 \pm 0.42$ & $3.97 \pm 0.20$ & $1.61 \pm 0.14$ \\
\hline T-gdh 1 & $0.95 \pm 0.01 * *$ & $0.30 \pm 0.02 * *$ & $0.65 \pm 0.13 *$ & $4.52 \pm 0.27$ & $2.03 \pm 0.10^{*}$ \\
\hline T-gdh 2 & $1.00 \pm 0.03 *$ & $0.22 \pm 0.04$ & $0.62 \pm 0.10$ & $4.61 \pm 0.35$ & $1.89 \pm 0.13$ \\
\hline \multirow[t]{2}{*}{ T-gdh 3} & $1.12 \pm 0.35$ & $0.28 \pm 0.16$ & $0.61 \pm 0.01 *$ & $5.98 \pm 0.18^{* *}$ & $1.84 \pm 0.17$ \\
\hline & Gln & Gly & Ala & Val & Met \\
\hline Non-transgenic plant & $4.34 \pm 0.39$ & $0.21 \pm 0.05$ & $0.30 \pm 0.17$ & $0.37 \pm 0.03$ & $0.02 \pm 0.01$ \\
\hline T-gdh 1 & $5.43 \pm 0.66$ & $0.20 \pm 0.01$ & $0.52 \pm 0.02$ & $0.32 \pm 0.07$ & $0.03 \pm 0.01$ \\
\hline T-gdh 2 & $5.53 \pm 0.29 *$ & $0.18 \pm 0.06$ & $1.59 \pm 0.88$ & $0.30 \pm 0.08$ & $0.03 \pm 0.01$ \\
\hline \multirow[t]{2}{*}{ T-gdh 3} & $5.58 \pm 0.34^{*}$ & $0.15 \pm 0.05$ & $0.66 \pm 0.38$ & $0.25 \pm 0.09$ & $0.03 \pm 0.01$ \\
\hline & Ile & Leu & Tyr & Phe & GABA \\
\hline Non-transgenic plant & $0.49 \pm 0.06$ & $0.46 \pm 0.16$ & $0.40 \pm 0.16$ & $0.17 \pm 0.05$ & $0.76 \pm 0.27$ \\
\hline T-gdh 1 & $0.36 \pm 0.07$ & $0.31 \pm 0.09$ & $0.36 \pm 0.10$ & $0.24 \pm 0.07$ & $0.87 \pm 0.24$ \\
\hline T-gdh 2 & $0.28 \pm 0.01$ & $0.23 \pm 0.02$ & $0.26 \pm 0.03$ & $0.13 \pm 0.01 * *$ & $0.76 \pm 0.21$ \\
\hline \multirow[t]{2}{*}{ T-gdh 3} & $0.26 \pm 0.10$ & $0.21 \pm 0.04$ & $0.24 \pm 0.08$ & $0.17 \pm 0.14$ & $0.54 \pm 0.06$ \\
\hline & Lys & His & Arg & Pro & Total \\
\hline Non-transgenic plant & $0.09 \pm 0.03$ & $0.19 \pm 0.13$ & $0.25 \pm 0.09$ & $0.01 \pm 0.01$ & $17.70 \pm 3.06$ \\
\hline T-gdh 1 & $0.10 \pm 0.02$ & $0.19 \pm 0.08$ & $0.15 \pm 0.04 * *$ & $0.19 \pm 0.03 * *$ & $19.32 \pm 2.60$ \\
\hline T-gdh 2 & $0.10 \pm 0.04$ & $0.18 \pm 0.12$ & $0.16 \pm 0.06$ & $0.02 \pm 0.01 * *$ & $19.19 \pm 2.67$ \\
\hline T-gdh 3 & $0.09 \pm 0.06$ & $0.28 \pm 0.31$ & $0.15 \pm 0.10$ & $0.18 \pm 0.03 * *$ & $19.65 \pm 3.34$ \\
\hline
\end{tabular}

Values are means \pm S.E.M of results from three leaves in each case.

** Significant difference at the $1 \%$ level when compared with the non-transgenic plant.

* Significant difference at the $5 \%$ level when compared with the non-transgenic plant (Student's $t$-test).

\section{Discussion}

In the present study, transgenic tomato plants that overexpressed a gene for NADH-dependent glutamate dehydrogenase (legdh1) from tomato were obtained. We observed that the NADH-GDH activity in the leaves of the transgenic tomato plants was about twice that of the non-transgenic tomato plant (Table 1). As shown in Table 2, the levels of total free amino acids were much higher (about double) in transgenic tomato fruits than in the non-transgenic tomato fruits at the later stage of ripening (six to seven weeks after flowering) and the level of glutamate was 2.1 to 2.4 times higher than that in the non-transgenic controls. The strong aminating activity of NADH-GDH was consistent with the increased levels of glutamate in the transgenic tomato fruits.

In the non-transgenic tomato fruits, $\gamma$-aminobutyric acid (GABA) was the predominant amino acid at the early stages of fruit ripening and the level of glutamate increased to close to $60 \%$ of that of the total free amino acids, with a decrease in the levels of GABA, at the later stages (six to seven weeks after flowering). These data are similar to those reported for a tomato variety Cherry by Boggio et al. (2000). Boggio et al. (2000) reported that NADH-GDH occurred almost exclusively in the extracts of red fruits, while glutamine synthetase (GS) was found principally in the green fruits of non-transformed tomato plants. The high levels of glutamate in the ripening fruits were correlated with increased levels of NADH-GDH, aspartate aminotransferase and NADH-malate dehydrogenase and, also, with a decrease in the levels of GS.

Those results indicated that the accumulation of glutamate increased by the enhancement of the GDH activity in ripening tomato fruits, and that for the enhancement of the GDH activity it was important to introduce the legdhl gene into plants.

In a previous study (Kisaka and Kida 2003), we developed transgenic tomato plants that overexpressed the gdhA gene for NADPH-dependent glutamate dehydrogenase from Aspergillus nidulans (Hawkins et al. 1989) in order to increase the glutamate content of tomato fruits. Significant increases in the levels of aspartic acid, asparagine, alanine and GABA, which belong to the glutamate family, was also observed in the transgenic tomato fruits harboring the $g d h A$ transgene from Aspergillus (Kisaka and Kida 2003). These results bear a strong resemblance to those in the present study, suggesting that the accumulation capacity of free amino acids in tomato fruits was limited.

The increase in the glutamate content of the transgenic tomato leaves was not as conspicuous as that in the transgenic fruits. Ferrario-Mery et al. (2001) reported that the aminating activity of NADH-GDH markedly increased in transgenic tobacco plants with less than $60 \%$ of the normal level of Fd-GOGAT after transfer from an atmosphere with an elevated level of $\mathrm{CO}_{2}$ to air. They suggested that the glutamate pool in leaves might be stabilized by the compensatory activity of NADH-GDH when the level of Fd-GOGAT 
became limiting. Glutamate synthesized in source organs is consumed when it acts as a donor of amino groups for the synthesis of various metabolites in cells or is transported to sink organs. Therefore, it might be difficult to detect on increase in the amount of glutamate in source organs, such as leaves, that overexpress foreign genes.

Fruits are typical sink organs and depend on the translocation of sucrose, amino acids and organic acids from source organs and the rate of import of photoassimilates from leaves is governed by the metabolic activity of the fruits (Ho 1988). In the leaves of our transgenic tomato plants, the levels of amido-type amino acids, such as asparagine and glutamine, which are known to be transported from source to sink organs, were higher (about 1.5-fold) than those in the control plants (Table 3 ). The remarkable increase in the levels of glutamate in the transgenic tomato fruits that overexpressed the ledghl gene might have been due not only to the high aminating activity of NADH-GDH in fruits but also to increased supplies of amido-type amino acids to the sink organs (fruits) as a source of nitrogen.

In conclusion, attempts were made to introduce the legdhl gene into tomato plants in order to increase the level of glutamate in fruits. As a result, the transgenic fruits accumulated free amino acids, especially glutamate.

\section{Acknowledgements}

The authors are grateful to Dr. Kenzo Nakamura (Nagoya University) for kindly providing the binary vector pIG121-Hm.

\section{Literature Cited}

Boggio,S.B., J.F.Palatnik, H.W.Heldt and E.M.Valle (2000) Changes in amino acid composition and nitrogen-metabolizing enzymes in ripening fruits of Lycopersicon esculentum Mill. Plant Sci. 159: 125-133.

Ferrario-Mery, S., M. Hodges, B. Hirel and C.H. Foyer (2002) Photorespiration-dependent increases in phosphoenolpyruvate carboxylase, isocitrate dehydrogenase and glutamate dehydrogenase in transformed tobacco plants deficient in ferredoxindependent glutamine- $\alpha$-ketoglutarate aminotransferase. Planta 214: 974.

Ficarelli,A., F.Tassi and F.M.Restivo (1999) Isolation and characterization of two cDNA clones encoding for glutamate dehydrogenase in Nicotiana plumbaginifolia. Plant Cell Physiol. 40: 339-342.

Fuke,S. and S.Konosu (1991) Taste-active components in some foods: a review of Japanese research. Physiol. Behavior 49: 863-868.

Gallardo,F., S.Galvez, M.A.Quesada, F.M.Canovas and I.N.Castro
(1988) Glutamine synthetase activity during the ripening of tomato. Plant Physiol. Biochem. 26: 747-752.

Gallardo,F., F.R.Canton, A.Garcia-Gutierrez and F.M.Canovas (1993) Changes in photorespiratory enzymes and glutamate synthases in ripening tomatoes. Plant Physiol. Biochem. 31: 189-196.

Hawkins, A., S.J.Gurr, P.Montague and J.R.Kinghorn (1989) Nucleotide sequence and regulation of expression of the Aspergillus nidulans gdhA gene encoding NADP-dependent glutamate dehydrogenase. Mol. Gen. Genet. 218: 105-111.

Ho,L. (1988) Metabolism and compartmentation of imported sugars in sink organs in relation to sink strength. Annu. Rev. Plant Physiol. Plant Mol. Biol. 39: 355-378.

Honda,H. and A.Hirai (1990) A simple and efficient method for identification of hybrids using non-radioactive rDNA as probe. Breed. Sci. 40: 339-348.

Hood,E.E., G.L.Halmer, R.T.Fraley and M.D.Chilton (1986) The hypervirulence of Agrobacterium tumefaciens A281 is encoded in a region of pTiBo542 outside of T-DNA. J. Bacteriol. 168: 1291-1301.

Kisaka,H. and T.Kida (2003) Transgenic tomato plant carrying a gene for NADP-dependent glutamate dehydrogenase $(g d h A)$ from Aspergillus nidulans. Plant Sci. 164: 35-42.

Lightfoot,D.A. and L.M.Long (1999) Plants containing a bacterial gdhA gene and methods of use thereof. Patent; US 5998700.

Loulakakis, K.A. and K.A. Roubelakis-Angelakis (1991) Plant $\mathrm{NAD}(\mathrm{H})$-glutamate dehydrogenase consists of two subunit polypeptides and their participation in the seven isoenzymes occurs in an ordered ratio. Plant Physiol. 97: 104-111.

Loulakakis, K.A. and K.A.Roubelakis-Angelakis (1996) The seven $\mathrm{NAD}(\mathrm{H})$-glutamate dehydrogenase isoenzymes exhibit similar anabolic and catabolic activities. Physiol. Plant 96: 29-35.

Melo-Oliveira,R., I.C.Oliveira and G.M.Coruzzi (1996) Arabidopsis mutant analysis and gene regulation define a nonredundant role for glutamate dehydrogenase in nitrogen assimilation. Proc. Nat. Acad. Sci. USA 93: 4718-4723.

Mungur,R., A.D.Glass, D.B.Goodenow and D.A.Lightfoot (2005) Metabolite fingerprinting in transgenic Nicotiana tabacum altered by the Escherichia coli glutamate dehydrogenase genes. J. Biomed. Biotechnol. 2005: 198-214.

Murashige,T. and G.Skoog (1962) A revised medium for rapid growth and bioassays with tobacco tissue culture. Physiol. Plant. 15: 473-497.

Purnell,M.P., G.R.Stewart and J.R.Botella (1997) Cloning and characterization of a glutamate dehydrogenase cDNA from tomato (Lycopersicon esculentum L.) Gene 186: 249-254.

Roekel,T.S.C., B.Damm, L.S.Melcher and A.Hoekema (1993) Factor influencing transformation frequency of tomato (Lycopersicon esculentum). Plant Cell Rep. 12: 644-647.

Turano,F.J., S.S.Thakkar, T.Fang and J.M.Weisemann (1997) Characterization and expression of $\mathrm{NAD}(\mathrm{H})$-dependent glutamate dehydrogenase genes in Arabidopsis. Plant Physiol. 113: 1329 1341. 